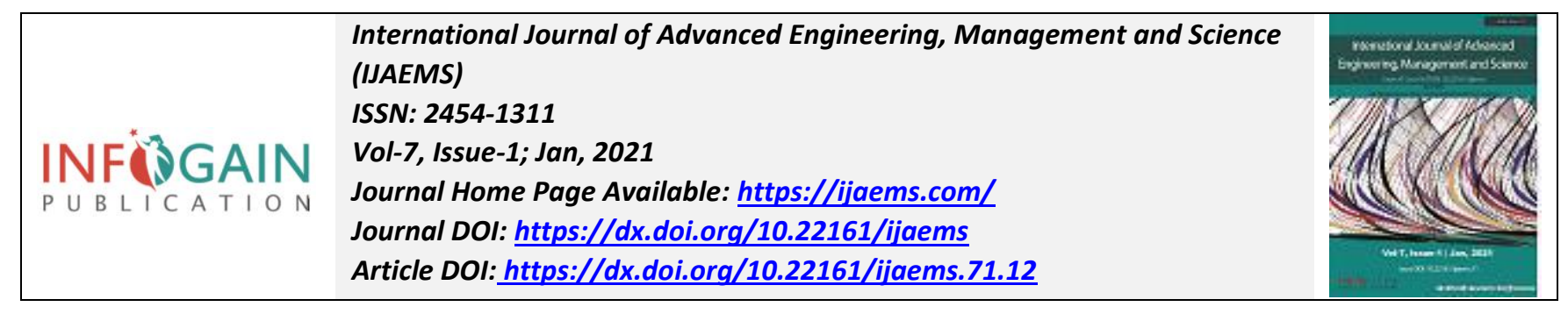

\title{
Contextualizing Digital Innovation and Artificial Intelligence to Sustainable Development
}

\author{
Sunil K. Mishra ${ }^{1}$, Parul Mishra ${ }^{2}$ \\ ${ }^{1}$ Associate Professor of English, Amity University, Haryana, India \\ ${ }^{2}$ Assistant Professor of English, G D Goenka University, Gurgaon Haryana, India
}

Received: 29 Nov 2020; Received in revised form: 15 Jan 2021; Accepted: 25 Jan 2021; Available online: 31 Jan 2021 (C)2021 The Author(s). Published by Infogain Publication. This is an open access article under the CC BY license (https://creativecommons.org/licenses/by/4.0/).

\begin{abstract}
The analysis is done on digital technology to know its role to promote sustainability. The analysis of big data, artificial intelligence and machine learning technologies reveal these facts. The digital technology is helpful to create smart electrical grids. It also creates optimized energy system to save energy and enhances its forecasting ability. The energy plant assessment is done by the application of artificial intelligence. Clean power is thus provided by the artificial intelligence use. Smart homes and cities can be created by the digital technology. Energy efficient building can be created as well as automation of urban planning can be done. The sustainable use of land is also possible with the artificial intelligence technology use. It is found that nutrition and precision agriculture are possible with artificial intelligence application. Crop issues are also identified by applying digital technology in the agricultural sector. Deforestation issue can also be effectively addressed by applying the digital technology. The production and consumption can become sustainable with better monitoring and transparency in supply chain. Smart recycling system and fresh food replenishment can be obtained with the use of digital technology. The transport system can be improved as artificial intelligence enabled cars and autonomous vehicles can optimize the traffic flow, reduce accidents, and improve cost efficiency. Charging infrastructure supportive for environment can also be created using digital technology.

On the other side, there are several drawbacks associated with the artificial intelligence. One is inequality caused using this technology as the equipment of artificial intelligence are not accessible to all equally. Another drawback of the digital technology is unethical use as the digital technology may be used for unethical purposes and may promote nationalism. It may erode the social cohesion fabric too. Other drawbacks such as improper distribution of technology and gender inequality also suggest that artificial intelligence as a form of digital technology may not be completely appropriate to support sustainable development. Thus, the findings suggest that the digital technology has a mixed impact on sustainability.
\end{abstract}

Keywords_-Digital Innovation, Artificial Intelligence, mobility over demand, Climate change.

\section{INTRODUCTION}

Business operates now with a focus to build sustainability. The companies now bear some responsibilities for the environmental and social problems. Therefore, the conventional strategies that considered only profit maximization of shareholders are left by the organizations. Now, the organizations are engaged in charitable giving to build their corporate images (Long).
The challenges to environment are many such as challenge of achieving water security, and clean air. Challenges such as addressing climate change and maintaining biodiversity are also present. Climate change is reflected by the highest concentration of greenhouse gases level in the environment 3 . The biodiversity is losing rapidly, and it may cause mass extinction as the scientists believe that biodiversity loss would be 50 percent till the 
end of the century (McKie). The deforestation rate causing significant rainfall drops in the Amazon basin (Cebellos). Ocean acidification erodes coral reefs and marine biodiversity (Arc Centre of Excellence for Coral Reef Studies, James Cook University [media realease], ). Air quality is not met as specified by world health organization for 92 percent of people globally (World Health Organization). Due to air pollution one death among eight people is caused (World Health Organization). These figures suggest that sustainability development is crucial to address changes in environment. It is also found that many kinds of natural loss events are experienced (Munich re). These issues present several challenges for the world community. Therefore, it is crucial to consider how sustainability can be fostered.

In this regard, the digital innovation can contribute to the sustainability. In this report, exploration of digital technology contribution to the sustainability through innovations is examined critically. For this purpose, different technologies used by the organizations to foster sustainability are discussed. Digital technology such as artificial intelligence, drone technology, machine learning are most important digital technologies that transform the work. Digital transformation has taken place with artificial intelligence application. The digital technologies now modify the experiences of customers as well as business processes. In this regard, artificial intelligence as a digital technology transformation enabler plays a crucial role. Thus, the report is focused on how a digital technology such as artificial intelligence contributes to the sustainability. For digital transformation, artificial intelligence technology is necessary; therefore, machine learning and artificial intelligence are part of business strategies of many organizations (Ribeiro). The digitalization takes place with big data, internet penetration, enhanced computing power and artificial intelligence. Therefore, the focus is to know how the digital technology such as artificial intelligence contributes to achieve sustainable development goals proposed by UN.

\section{ROLE OF ARTIFICIAL TECHNOLOGY TO BUILD SUSTAINABILITY}

Artificial technology provides greater support to build sustainability. The technology innovative features support energy system forecasting and are helpful in urban planning. The technology is also assistive to forecast weather for crop management. The technology contributes well to develop sustainable supply chain through monitoring. Thus, the fourth industrial revolution that includes innovative technologies is able to address the environmental issues. The global environment can be managed with the digital technology application.

Artificial intelligence shows potential to manage climate change. Machine learning is now used to identify demand of energy and energy generation in real time that helps to create optimized smart grids. Such ability of artificial intelligence also enhances efficiency, decrease poor sustainability, and balancing of power (Forum). One example of it is Agder Energi that uses the artificial intelligence to predict energy needs. Such ability reduces the need to keep idle capacity. Energy efficiency is also developed by the neural network. One example of it is the company DNV GL that uses sensors for the purpose of remote monitoring of sites as well as forecasting of energy resource (DNV GL). This helps the company to enhance efficiency and control.

Machine learning algorithm also helps in buildings by using smart sensors to predict requirements of energy and their cost (PwC). Artificial intelligence is used for heating and lighting for streets to building for optimized energy use. The company JTC uses artificial intelligence to enhance energy efficiency. These examples suggest that artificial intelligence is very useful to support sustainable development.

The machine learning algorithms are used to create efficient building in terms of energy use. To support transportation, machine learning helps in optimize navigation through Google maps to enhance safety and avoid traffic flow. Such abilities are helpful in urban level planning to ensure efficient city mobility by considering the transport demand pattern, and optimization of routes to enhance safety of people ( $\mathrm{PwC})$. The artificial intelligence powered vehicles have machine vision algorithms that can enable mobility over demand (WEF). Therefore, connected artificial guided vehicles can reduce greenhouse gases in urban transport and this is done by eco driving algorithm, route optimization, ride sharing services and reduction in congestion.

Artificial intelligence can transform ways for monitoring of habitats. Artificial intelligence technology is helpful to detect the changes in land such as forest cover changes, change in vegetation and this technology is also assistive to monitor floods. One organization called planet Watcher insights by using artificial intelligence technology addresses challenges caused by climate change such as droughts, damage, fire and pests. Invasive species can be threat to the local biodiversity of forests. In this regard, the machine learning can be assistive to recognize these invasive species as well as diseases to eliminate them. Blue river technology uses artificial technology to address invasive weeds. 
Wildlife trade is a threat to local biodiversity richness and needs protection. This wildlife trade is protected when artificial intelligence along with drone technology monitors forests. For example, an organization Neurala protects elephants and rhinos in Africa through use of drone aerial footage and artificial intelligence 34 . The sensors provide movement of objects in jungles and in real time, poachers, vehicles and animals can be identified during night and daytime. These facts about artificial intelligence reveal that artificial intelligence technology is very much crucial to protect environmental biodiversity and resources.

Artificial technology provides new ways to manage oceans in sustainable ways. Artificial intelligence along with other technologies helps to collect valuable data to maintain fish sustainability. Such technologies also help to protect natural habitat and marine species. The technologies enable to know the climate change impact as well. Illegal fishing is a big worry as many reserves of marine fishes are ending fast. By applying machine learning techniques, patrol schedules in marine areas are scheduled properly and satellite data identifies the illegal activities of fishing. Such tracking assists to control fisheries reserves and prevent overfishing. To protect species, there are systems of machine learning enabling to tract locations as well as numbers of invasive species. For example, drones are used to collect information about mucus samples of whales to measure their health in real time. Artificial powered robots are also helpful to monitor the pollution levels as well as temperature change. The $\mathrm{PH}$ level of oceans is also changed by climate change. For example, NASA, through machine learning can predict the oceanic phytoplankton of the world. There are technologies for ocean exploration with progress in artificial intelligence and robotics to assist in ocean floor survey. These technologies can detect species and manage nature resources ( $\mathrm{PwC})$.

Water is a valuable for people. With the use of artificial intelligence, now the project water and reservoirs can be better managed. Policies decisions regarding water management are enhanced by applying artificial intelligence technique. Smart meter assets are managed by artificial intelligence use 40. Such approach helps to detect real time water flow, leaks in water, and malfunctioning meters. The water smart software enables to read water flow as well as identify sport anomalies. A company named Syracuse, N.Y. by use of artificial intelligence identifies the leaks prone pipes for water management. These examples suggest that artificial intelligence plays a significant role in water saving efforts and management of water resources. The artificial intelligence system also enables to minimize the loss of water.
The artificial intelligence can forecast the patterns of weather and also analyze water conditions and soil conditions. This information is helpful to predict future drought conditions to avoid any negative effect on communities. Machine learning is used with physical models to evaluate plans of crisis management and results of decisions of water planning. Thus, the innovative technology such as artificial intelligence is found to provide significant support to manage water resources optimally (PwC).

Machine learning is also used for air quality measurement. The data obtained from environment are real time data and it helps to build filtration efficiency. Artificial intelligence can assist in real time quality of air monitoring and one example of is the AirTick Company that uses smartphones cameras to know the level of air pollution (Rutkin). There are many forecasting tools development by companies such as IBM, AirVisual and others to predict air quality. Thus, the sustainable solutions provided by the artificial intelligence to manage air quality reveal that the new technologies have great potential to address environmental issues and foster sustainability.

It is also found that Artificial intelligence helps to provide warning regarding quality of air. Traffic flow in the urban cities is optimized by sensors and cameral through use of artificial intelligence technology 50. Artificial intelligence is also able to improve the battery design therefore, the efficiency and effectiveness of electric vehicles is enhanced. The air quality is also improved by artificial intelligence technology in the battery design (PwC).

Various emerging applications related to disaster resilience and weather is focused to create prediction about natural disasters and extreme weather conditions. In this regard, the predictive analytics provided by the artificial intelligence helps the governments to monitor the natural disasters such as floods, windstorms, and tremors. Governments and communities devoted to science can also predict other kinds of natural hazards. Sea level changes can also be predicted by the artificial intelligence technology (PwC).

The artificial intelligence technology is also used to communicate information about disaster to the public. Real time response can be obtained through artificial intelligence use. There are various tools and techniques such as seismic data, deep learning algorithm and others that can prioritise the work of relief during disaster. The artificial intelligence can identify which part of the city is required attention more than others during disaster management.

It is also found that apart from addressing environmental challenges, artificial intelligence creates 
game changers scenario. The game changer impact is seen by transformational impact. Artificial intelligence can potentially disrupt the current approaches or alter them. It is revealed that artificial intelligence enhances network efficiency and navigation. EV charging has become cheaper with artificial intelligence use. Connected autonomous fleets transition may vary between countries; however, there is a possibility that fully autonomous urban fleets can be a reality (PwC).

Benefits related to artificial intelligence use for environment protection reveals that interconnected databases with artificial intelligence use can preserve the environment. Thus, the artificial intelligence progress can support to address the climatic change and the technology can also support such energy systems producing low carbon. The technology enables to integrate renewable energy. The health of ecosystem can be improved as marine pollution can be decreased by identifying of oil spills (Keramitsoglou). It is found that digital technology can help to classify vegetation types as well (Mohamadi). Decertification trends can be known by applying artificial intelligence technology to preserve environment.

\section{ARTIFICIAL INTELLIGENCE AND SUSTAINABLE AGRICULTURE}

The role of artificial intelligence in sustainable agriculture is also found. Farm level data through precision agriculture and automated data collection is possible with use of artificial intelligence. The artificial intelligence is helpful to detect the crop disease as well as issues. Timed nutrition is also provided to livestock by applying artificial intelligence technique. This technique is also assistive to optimize the inputs of agriculture and their returns. Thus, the artificial intelligence is helpful to improve the resource efficiency of agriculture. Disease management is crucial for the farmers. Artificial intelligence in this respect helps farmers to manage diseases effectively. Weed management is also done by this technology. Yield prediction is known by the application of this technology (Bannerjee).

It is found that digital technology can assist the companies to provide sustainable solutions to the customers. The sustainability related values of the consumers can be monetized by the companies. Innovative customized solutions can be provided to the suppliers by companies as well. These facts suggest that digital technologies provide many benefits to ensure better sustainable future. On the other hand, the analysis is incomplete without considering the limitation of digital technology and for this purpose; the drawbacks of artificial intelligence are explained.

\section{LIMITATION OF DIGITAL TECHNOLOGY}

The example of artificial intelligence reveals that it can provide various benefits in terms of sustainable development goals achievements. Artificial intelligence can create smart cities with low carbon production. Connected autonomous vehicles are reality; electricity sector can optimize its production and use. However, still the requirements to create big data centers with cooling system and reduced use of electricity needs to be achieved. Human knowledge embedding in the artificial intelligence system is also very much required.

\section{Inequality promotion}

It is also found that artificial intelligence may lead to inequality and may require additional qualification for any kind of work.

\section{Unethical use of artificial intelligence}

The drawback of artificial intelligence reflects that it is created according to values and needs of a country. Artificial intelligence used along with big data in those countries where transparency, ethical monitoring and democratic control are not sufficient, such technology use can lead to biased election results, hate towards minorities, and rise of nationalism. Therefore, the use of artificial intelligence may disrupt the social fabric of the society. Human rights may be compromised, and democratic principles may be defeated (Helbing). The artificial intelligence is also used for citizen scores development. Such score is generally used to control the behaviour of people (Nagler). This kind of score reveals that human rights are violates and artificial intelligence can be misused. Another potential drawback of artificial intelligence is not providing sufficient data to the public about how the data will be used and what consequences they will have on their lives.

\section{Improper distribution of artificial intelligence technology}

It is also imperative to know that distribution of artificial intelligence is not even. It is found that artificial intelligence enhanced equipment for agriculture is not evenly distributed to all farmers as small farmers cannot access these equipments. Thus, the production of agriculture shows an increased gap between large producers and small producers in agriculture sector (Wegren). This fact reveals that the goal to eliminate hunger that is a sustainable development goal is not achieved by the digital technology.

\section{Gender inequality}

Artificial intelligence is also found to increase gender inequality. This inability of artificial intelligence to achieve sustainable development goal five on gender equality reveals that sustainable development is not 
achieved completely by the digital technology. It is found that machine learning algorithm causes discrimination and societal bias against girls and women. Word embeddings also cause to exacerbate gender stereotype thinking.

The next thing worrying about artificial intelligence lack of ability for sustainable development is lack of diversity. The artificial workforce does not consist racial, ethnic and gender diversity that is a worrisome factor (NSF - National Science Foundation). It is found that if the future markets are dependent on only data analysis and if these resources are not available to the low income or middle-income countries, the economical gap can further exacerbate inequality (Bissio). This can significantly impact the number eight sustainable goal proposed by UN. This goal is associated with economic growth and decent work. The inequality also affects innovation, infrastructure and industry sustainable goal. The sustainable goal of reduced inequalities is also not achieved when artificial intelligence spreads more inequality by its application. According to Brynjolfsson and McAfee, artificial intelligence can spread more inequality among countries (Brynjolfsson). Old jobs replaced by the new jobs requires from workers to develop new skills and this means those who have skills can be benefitted. However application of artificial technology rewards educated people more than less educated people. It is also found that automation causes income inequality between corporate owners and workers.

It is also found that artificial intelligence has negative impact on use of social media by showing only that content to the users that suit their preconceived notions. Such social media use can cause erosion in social cohesion as well as political polarization (Francescato). This cannot help to achieve the sustainable goal 10 to reduce inequalities. It is also found that there are many discriminatory challenges associated with the use of targeted online advertising by using this technology (Dalenberg).

\section{CONCLUSION}

The analysis of role of digital technology reveals that it has achieved good reputation to build sustainable future in the form of reduced energy, reduced carbon emission, and reduced GHG gases emissions. The technology enables efficient management of agricultural issues. Farmers are benefitted immensely by the application of this digital technology. The smart cities creation through digital technology is a reality. Connected cars and autonomous vehicles movement are also possible with the artificial intelligence technology that helps to achieve sustainable development as people can avoid traffic congestion and route management can be optimum.
However, with these achievements, there are certain issues related with the use of artificial intelligence, machine learning and big data. It is found that inequality is exacerbated with the use of the digital technology. It is found that inequality is caused due to the non-availability of costly equipments available for big farmers in developed countries. The inequality is also exacerbated between developed and developing countries. It is also found that racial thinking and prejudice are promoted by selected targeting with the application of artificial intelligence on social media. The findings also reveal that various sustainable development goals proposed by UN to achieve are not met. Thus, the digital technology role to meet sustainable development goals provides mixed results. On one side, it provides good benefits; however, it also causes harms to the society. Finding reveals that digital technology drawbacks need to be addressed to obtain its true benefits for sustainable development.

\section{REFERENCES}

[1] Arc Centre of Excellence for Coral Reef Studies, James Cook University [media realease], . Scientists Assess Bleaching Damage on Great Barrier Reef. 2016. <https://www.coralcoe.org.au/media-releases/scientistsassess-bleaching-damage $>$.

[2] Bannerjee, G., Sarkar, U., Das, S., \& Ghosh, I. "Artificial intelligence in agriculture: A literature survey." International Journal of Scientific Research in Computer Science Applications and Management Studies, 7(3) (2018): $1-6$.

[3] Bissio, R. "Vector of hope, source of fear. ." Spotlight Sustain. Dev. (2018): 77-86.

[4] Brynjolfsson, E. \& McAfee, A. "The Second Machine Age: Work, Progress, and Prosperity in a Time of Brilliant Technologies (W. W. Norton \& Company, 2014).” (2014).

[5] Cebellos, G, et al. Accelerated Modern Human-Induced Species Losses: Entering the Sixth Mass Extinction, Science Advances. 2015. <https://www.science.org/doi/10.1126/sciadv.1400253>.

[6] Dalenberg, D. J. "Preventing discrimination in the automated targeting of job advertisements." Computer law \& security review, 34(3) (2018): 615-627.

[7] DNV GL. Making Renewables Smarter: The benefits, risks, and future of artificial intelligence in solar and wind. 2021. <https://www.dnvgl.com/publications/making-renewablessmarter-104362>.

[8] Forum, World Health. Top Ten Urban Innovations. 2015. <http://www3.weforum.org/docs/Top_10_Emerging_Urba n_Innovations_report_2010_20.10.pdf >.

[9] Francescato, D. "Globalization, artificial intelligence, social networks and political polarization: New challenges for community psychologists. ." Community psychology in global perspective, 4(1), (2018): 20-41.

[10] Helbing, D., \& Pournaras, E. "Society: Build digital democracy. .” Nature News, 527(7576) (2015): 33. 
[11] Keramitsoglou, I., Cartalis, C., \& Kiranoudis, C. T. "Automatic identification of oil spills on satellite images. ." Environmental modelling \& software, 21(5) (2006): 640652.

[12] Long, B.T. Sustainable Business Strategy. 2020. $<$ https://www.researchgate.net/publication/332414437_Sus tainable_Business_Strategy>.

[13] McKie, R. Biologists think $50 \%$ of species will be facing extinction by the end of the century. 2017. <https://www.theguardian.com/environment/2017/feb/25/h alf-all-species-extinct-end-century-vatican-conference $>$.

[14] Mohamadi, A., Heidarizadi, Z., \& Nourollahi, H. "Assessing the desertification trend using neural network classification and object-oriented techniques. .” J. Fac. Istanb. Univ, 66 (2016): 683-690.

[15] Munich re. Data on natural disaster since 1980. 2021. <https://www.munichre.com/en/solutions/for-industryclients/natcatservice.html>.

[16] Nagler, J., van den Hoven, J., \& Helbing, D. “An extension of asimov's robotics laws." $\underline{\text { In Towards Digital }}$ Enlightenment (pp. 41-46). Springer, Cham. (2019).

[17] NSF - National Science Foundation. Women and Minorities in the S\&E Workforce (NSF - National Science Foundation). 2018.

[18] PwC. Fourth Industrial Revolution for the Earth Harnessing Artificial Intelligence for the Earth. 2018. <https://www.pwc.com/gx/en/sustainability/assets/ai-forthe-earth-jan-

2018.pdf?utm_campaign=sbpwc\&utm_medium $=$ site $\& u t m$ _source $=$ articletext $>$.

[19] - Fourth Industrial Revolution for the Earth Harnessing the 4th Industrial Revolution for Sustainable Emerging Cities. 2021. <https://www.pwc.com/gx/en/sustainability/assets/4ir-forthe-earth.pdf.>.

[20] - . Fourth Industrial Revolution for the Earth Harnessing the 4th Industrial Revolution for Sustainable Emerging Cities, November . 2021. $<$ https://www.pwc.com/gx/en/sustainability/assets/4ir-forthe-earth.pdf $>$.

[21] Ribeiro, J. How AI and Digital Transformation will change $\begin{array}{lll}\text { your business } & \text { forever. } & 2020 .\end{array}$ $<$ https://towardsdatascience.com/how-ai-and-digitaltransformation-will-change-your-business-foreverc7563c15c1b3>.

[22] Rutkin, A. Pic-scanning AI estimates city air pollution from mass of photos, New Scientist. 2016. $<$ https://www.newscientist.com/article/2076562-picscanning-ai-estimates-city-air-pollution-from-mass-ofphotos/.>.

[23] WEF. The driverless car revolution. 2021. $<$ http://reports.weforum.org/digital-transformation/thedriverless-car-revolution/. >.

[24] Wegren, S. K. "The "left behind": Smallholders in contemporary Russian agriculture ." Journal of agrarian change, 18(4) (2018): 913-925.

[25] World Health Organization . 7 Million Premature Deaths Annually Linked to Air Pollution. 2014. <http://www.who.int/mediacentre/news/releases/2014/airpollution/en/>.

[26] World Health Organization. Ambient (Outdoor) Air Quality and Health. 2016. <http://www.who.int/mediacentre/factsheets/fs313/en/.>. 